\title{
Evaluation of immunization coverage in the adult population of Canada
}

\author{
PHILIPPE DUCLOS DVM PhD
}

\begin{abstract}
P DucLos. Evaluation of immunization coverage in the adult population of Canada. Can J Infect Dis 1994;5(5):227-231. The immunization coverage of the adult population, availability of records and knowledge of proper schedules were assessed using the Canada Omnibus Survey, a door to door survey of a modified probability sample conducted four times a year. In total, 8021 interviews were completed over four periods. Only $43 \%$ of individuals 65 years of age or older reported receiving a dose of influenza vaccine during the year preceding the interview. Twenty-one per cent (38\% of those under 25 and $9 \%$ of those 65 and older) reported having an immunization booklet at home. Twelve per cent believed that there were no vaccines that they should be receiving regularly. Only $61 \%$ of those who believed they should receive some shots regularly knew when the next one was due. Overall, $48 \%$ felt they had enough information about the vaccines they should receive. This information will help target immunization programs for the adult population.
\end{abstract}

Key Words: Adult, Immunization coverage

\section{Évaluation de l'immunoprotection dans la population adulte du Canada}

RÉSUMÉ : L'immunoprotection de la population adulte, l'accessibilité des dossiers et la connaissance des calendriers d'immunisation ont été évaluées au moyen du Sondage Omnibus Canada, effectué de porte à porte quatre fois l'an, sur un échantillon à probabilité modifiée. En tout, 8021 questionnaires ont été remplis pour les quatre périodes. Quarante-trois pour cent seulement des individus de 65 ans ou plus ont déclaré avoir reçu un vaccin contre l'influenza au cours de l'année précédant l'entrevue. Vingt-et-un pour cent (38\% des répondants de moins de 25 ans et $9 \%$ des 65 ans et plus) ont dit avoir leur carnet de vaccination à la maison. Douze pour cent croyaient ne pas avoir à recevoir de vaccins régulièrement. Seulement $61 \%$ de ceux qui croyaient devoir recevoir des injections périodiques connaissaient la date de la suivante. Globalement, $48 \%$ se sont estimés suffisamment informés sur les vaccins qu'il leur faut. Ces renseignements aideront à mieux cibler les programmes d’immunisation pour la population adulte.

Bureau of Communicable Disease Epidemiology. Laboratory Centre for Disease Control, Ottawa, Ontario

Correspondence and reprints: Dr Philippe Duclos, Childhood Immunization Division, Bureau of Communicable Disease Epidemiology, Laboratory Centre for Disease Control, Tunney’s Pasture, Ottawa, Ontario K1A OL2. Telephone (613) 957-0325, Fax (613) 998-6413

Received for publication September 9, 1993. Accepted April 5, 1994 
$\mathrm{C}$ ANADIAN IMMUNIZATION PROGRAMS FOCUS ON INFANTS and children. Immunization of adults, however, is often overlooked and remains an inexpensive and costeffective measure for preventing the mortality and serious morbidity that is associated with infectious diseases that are vaccine preventable (1). The National Advisory Committee on Immunization (NACI) (2) recommends that: adults receive a tetanus-diphtheria (Td) booster every 10 years; persons over 65 years of age receive one dose of pneumococcal vaccine; and persons over 65 years of age receive influenza vaccine every year. Proper immunization with vaccines against diseases such as yellow fever, typhoid, meningococcal meningitis, hepatitis B, measles, mumps, rubella, poliomyelitis and Japanese encephalitis virus is also recommended for travellers and other specific high risk groups.

Monitoring vaccination coverage is of prime importance to assess the impact of immunization programs and to help improve surveillance of adverse vaccine reactions. Although it is acknowledged that vaccination is underused in the elderly (3), there is a general lack of information on immunization coverage of adults in Canada. Only one national survey examined the coverage with influenza vaccine (4). There is also a need to assess the availability of immunization records. These allow assessment of vaccine coverage and help ensure that vaccination is timely. Immunization records also facilitate the work of health care providers who determine which vaccine should be administered.

This study was, therefore, undertaken primarily to obtain an initial assessment of the immunization status of Canadians 18 years of age and older.

\section{PATIENTS AND METHODS}

Questions were added to the "Focus Canada Omnibus Survey". This door to door household survey of a modified probability sample is conducted four times a year by Environics Research Ltd, Toronto. The sample taken represents the Canadian population aged 18 years and older, with the exception of those living in Yukon or the Northwest Territories and those in the armed forces and various institutions (eg, hospitals, prisons). According to the 1992 postcensal estimates (5) the target population numbers around 20.5 million, of which approximately 3 million are over 65 years of age. The sampling model relies on stratification of the population by 10 regions (Atlantic; Montreal Census Metropolitan Area [CMA]; the rest of Quebec; Toronto СмA; the rest of Ontario; Manitoba; Saskatchewan; Alberta; Vancouver CMA; and the rest of British Columbia) and by four community sizes (1,000,000 inhabitants or more; 100,000 to $1,000,000$ inhabitants; 5000 to 100,000 inhabitants; and fewer than 5000 inhabitants). The sample also relies on quotas for sex, age and working status for women. Interviewees refusing to participate were replaced by others with the same characteristics up to achievement of quota for each group.

Only one respondent was interviewed per household. Interviews were conducted in French or English according to the choice of the interviewee. The survey was conducted four times during the year to achieve sufficient sample size and to account for seasonal variation. Questions included history and type of immunization (including all vaccines they might have received) during the year before the interview, availability of immunization records and perceived knowledge of immunization practices. The questionnaires were distributed, through regional supervisors, to approximately 150 experienced interviewers across the country. A show card with names of all vaccines (and alternate names) was used to help interviewees remember vaccines that they may have received. To check the quality of the work completed and the accuracy of the indicated responses, $10 \%$ of each interviewer's respondents were re-contacted to confirm participation in the questionnaire and that the questionnaire was administered properly. Answers given by respondents in these interviews had to correspond with answers given at the time of the interview or the interview was discarded along with other interviews conducted by the interviewer involved. Data entered into the computer were weighted according to the actual population of each of the regions. Other proprietary questions were included in the various cycles for clients other than Health Canada. Content of the questions was not related to health and should not have had an impact on immunizationrelated questions.

The effects of several demographic variables were evaluated, including age, sex, region of residency and community size, number of years of school completed, occupation and household income.

Ninety-five per cent cIs were calculated using the normal approximation (6). Estimated proportions in excess of $0.5 \%$ were rounded to the nearest integer.

Analysis compared results from one cycle of the study with the other to detect seasonal trends and to assess consistency in the results. For general analysis, and since sampling was independent from one cycle to the other, data from all four cycles were pooled together and treated as a unique sample.

Information on the vaccine distribution per calendar year was obtained from and released with the agreement of the manufacturers.

\section{RESULTS}

A total of 8021 interviews was completed: 2012 were carried out between July 15 and August 15, 1991; 2003 between October 25 and November 19, 1991; 2001 between February 22 and March 21, 1992; and 2005 between May 18 and June 14, 1992.

Table 1 presents the estimated proportion and 95\% CI of Canadians aged 18 years and older who felt that 
TABLE 1

Interview results showing estimated proportions and $95 \% \mathrm{Cl}$ of Canadians aged 18 years and older by region, sex, age, years of school and household income

\begin{tabular}{|c|c|c|c|c|c|c|}
\hline & \multicolumn{2}{|c|}{$\begin{array}{l}\text { Respondents think they know } \\
\text { enough about vaccinations they } \\
\text { should receive }\end{array}$} & \multicolumn{2}{|c|}{$\begin{array}{l}\text { Respondents think they should } \\
\text { receive doses of vaccines } \\
\text { regularly }\end{array}$} & \multicolumn{2}{|c|}{$\begin{array}{c}\text { Respondents with an } \\
\text { immunization booklet or } \\
\text { certificate }\end{array}$} \\
\hline & Percentage & $95 \% \mathrm{Cl}$ & Percentage & $95 \% \mathrm{Cl}$ & Percentage & $95 \% \mathrm{Cl}$ \\
\hline \multicolumn{7}{|l|}{ Region } \\
\hline Atlantic Provinces & 44 & $43-45$ & 8 & $6-10$ & 15 & $13-17$ \\
\hline Western Canada & 52 & $51-53$ & 10 & $9-11$ & 20 & $18-22$ \\
\hline \multicolumn{7}{|l|}{ Sex } \\
\hline Male & 44 & $42-46$ & 10 & $9-11$ & 23 & $22-24$ \\
\hline Female & 52 & $50-54$ & 13 & $12-14$ & 19 & $18-20$ \\
\hline \multicolumn{7}{|l|}{ Age (years) } \\
\hline 45 to 54 & 55 & $52-58$ & 10 & 8-12 & 18 & $16-20$ \\
\hline 55 to 64 & 49 & $46-52$ & 8 & $6-10$ & 15 & $13-17$ \\
\hline 65 and older & 56 & $53-59$ & 10 & $8-12$ & 9 & $7-11$ \\
\hline \multicolumn{7}{|l|}{ Years of school } \\
\hline 0 to 8 & 42 & $39-45$ & 9 & $7-11$ & 7 & $5-9$ \\
\hline 9 to 13 & 47 & $45-49$ & 9 & $8-10$ & 19 & $18-20$ \\
\hline$\geq 14$ & 52 & $50-54$ & 17 & $16-18$ & 30 & $28-32$ \\
\hline University degree & 57 & $54-60$ & 18 & $16-20$ & 29 & $26-32$ \\
\hline \multicolumn{7}{|l|}{ Household income $(\$)$} \\
\hline$<15,000$ & 45 & $42-48$ & 11 & $9-13$ & 14 & $12-16$ \\
\hline $15,000-24,999$ & 46 & $44-48$ & 10 & $9-11$ & 16 & $14-18$ \\
\hline
\end{tabular}

they knew enough about the vaccinations they should be receiving. These data are broken down by region, sex, age, years of school attended and household income. Other demographic variables not listed in Table 1, such as occupation and community size, did not have any statistically significant impact.

The estimated proportion and 95\% CI of adults who thought they should receive vaccines regularly are presented in Table 1. Only 61\% of these knew when their vaccinations were due.

Table 1 also presents the estimated proportion and 95\% CI of adults who had an immunization booklet or certificate. Eighteen per cent (95\% CI 16 to 20) of these indicated that they should receive vaccines regularly versus $10 \%(95 \%$ CI 9 to 11$)$ of those with no such records. Sixty-five per cent (95\% CI 59 to 71 ) of those with a record knew when they should receive their next vaccine versus $61 \%(95 \%$ cI 57 to 65$)$ who had no such records. Only 22\% (95\% CI 20 to 24$)$ of persons last immunized at their personal doctor's office had an immunization booklet or certificate versus 34\% (95\% CI
31 to 37) of persons who received their last shot at a clinic.

Thirty-four per cent (95\% cr 32 to 36) of interviewees indicated that they had received their last vaccine at the office of their personal or family doctor, $27 \%$ (95\% Cl 25 to 29$)$ at school, $14 \%(95 \%$ cl 12 to 16$)$ in a hospital, $14 \%(95 \% \mathrm{CI} 12$ to 16$)$ at a clinic, $4 \%(95 \%$ CI 3 to 5$)$ somewhere else, while $7 \%(95 \%$ cI 6 to 8$)$ did not remember where and $1 \%(95 \%$ cr 0 to 2$)$ indicated they had never been vaccinated.

Because administration of influenza vaccine is directly related to a particular season, only the third study cycle conducted in February and March 1992 was used to evaluate coverage of this vaccine during the fall-winter 1991-92 immunization campaign. The interviews were conducted soon after the immunization campaign; therefore, recollection was probably more vivid and pertinent to that season. Overall, 1 1\% (95\% CI 10 to 13) of the population 18 years of age and older stated they received influenza vaccine during the previous year (ie, received during the 1991-92 influenza 


\begin{tabular}{lc} 
TABLE 2 & \\
Average number of doses distributed for selected vac- \\
cines in Canada, calendar years 1991 and 1992 \\
\hline Vaccine & Average number of doses \\
\hline Japanese encephalitis & 7,000 \\
Pneumococcal & 29,000 \\
Cholera & 42,000 \\
Yellow fever & 60,000 \\
Typhoid & 95,000 \\
Tetanus & 257,000 \\
Hepatitis B & $533,000^{*}$ \\
Td and TdP & $1,250,000$ \\
Influenza & $3,650,000^{\dagger}$ \\
\hline
\end{tabular}

$.359,000$ doses in 1991 and 708,000 doses in $1992 ;{ }^{\dagger}$ Because of the important increase in the number of doses distributed from one season to the other and coverage figures for influenza being specific for the 1991-92 fall-winter immunization campaign only, the number of doses distributed for the season 1991-92 only are provided. Td Tetanus-diphtheria toxoid; TdP Td with pertussis

vaccine campaign). In the age group 18 to 44 years, only $3 \%(95 \%$ cI 2 to 4$)$ stated they received a dose versus $14 \%$ (95\% CI 11 to 17 ) of those 45 to 64 years and $43 \%$ (95\% ci 37 to 49$)$ of those 65 years and older.

For other vaccines, all cycles were pooled together for analysis. Despite some variations in the estimates over the four cycles, no seasonal variation was detected in the use of yellow fever, typhoid and cholera vaccines. This could be because these vaccines are most likely exclusively administered to travellers, and because of the size of the cIs and low proportion of people receiving them. No seasonal variation could be observed for the other vaccines.

Overall, $0.25 \%$ of respondents and $1 \%$ of those 65 years and older stated they received pneumococcal vaccine during the year before the interview. Based on the size of the population 18 years and older, this indicates that nearly 51,000 vaccine doses were given.

One per cent ( $95 \%$ ci 0 to 2 ) of all interviewees stated they received polio vaccine (oral or inactivated) during the year before the interview. This would account for nearly 210,000 doses a year being administered.

An estimated 6\% (95\% cl 5 to 7 ) of adults stated they received either $\mathrm{Td}$ or $\mathrm{Td}$ with pertussis (TdP). This would account for 1,234,000 doses annually. This vaccine was received by $9 \%$ of those persons 18 to 24 years of age, $7 \%$ of those 25 to 34 years, $5 \%$ of those 35 to 44 years, $4 \%$ of those 45 to 54 years, $4 \%$ of those 55 to 64 years and $3 \%$ of those 65 years of age and older. Thirty-six per cent of tetanus vaccines were received in a hospital setting. Only $2 \%(95 \%$ CI 1 to 3$)$ of adults indicated receiving diphtheria vaccine the previous year.

According to the replies, an estimated 2\% (95\% CI 1 to 3 ) of the adult population stated they received the hepatitis B vaccine. This would account for 369,000 doses. For persons 18 to 24 years of age, $2.6 \%$ stated they had received the vaccine versus $3.4 \%$ of those 25 to 34 years; $1.9 \%$ of those 35 to $44 ; 2.1 \%$ of those 45 to $54 ; 0.8 \%$ of those 55 to 64 ; and $0.2 \%$ of those 65 years of age and older.

An estimated $0.5 \%$ of the adult population stated they received the typhoid vaccine. This would account for 95,000 doses. An estimated $0.35 \%$ of adults received the cholera vaccine. This would be equivalent to 72,000 doses. An estimated $0.27 \%$ received the yellow fever vaccine, accounting for 55,500 doses.

The average numbers of doses of selected vaccines distributed in Canada in 1991 and 1992 appear in Table 2 .

\section{DISCUSSION}

Advantages of using such a survey to look at vaccine coverage are: first, the quick turnaround time (six to eight weeks) for results; second, use of an ongoing study that permits the evaluation of the impact of various demographic variables; and third, limited cost for well targeted questions.

Our study tried to take advantage of the personal recollection of an event by asking interviewees which vaccines they had received during the previous year instead of the date on which they had received specific vaccines during the same time period. Timely immunization coverage figures or compliance figures regarding NACI recommendations could be derived from knowing which vaccines were received during the year before the interview. This is particularly easy for vaccines that are administered annually, such as the influenza vaccine. Vaccines recommended by $\mathrm{NACl}$ to be given only every 10 years, such as Td, can be obtained by multiplying the proportion of persons receiving their dose on a given year by 10 . Ideally, with vaccines, such as pneumococcal vaccine, given only once, one should just have to consider people turning 65 years of age. However, due to the low use of this vaccine, this is not feasible. Nevertheless, because of such a low coverage as noted in our survey, one can probably rely on broad figures and on the number of doses distributed. The need to account for seasonality, the problems inherent in the lack of immunization records and the need to rely on personal recollection are the disadvantages of indirect evaluation of coverage.

As no definition was provided to them, it was left to the interviewees to define regular use for vaccines they should be receiving. This may have introduced some subjectivity in the responses to the question pertaining to the vaccines that interviewees should be receiving regularly because people may estimate that receiving vaccine every 10 years, for example, does not mean regularly.

Although Table 1 shows that the situation is not equal in all provinces and regions, and it may be tempting to infer that there is an east-west gradient, it is important to refrain from drawing such a conclusion. Within a region there may be provincial differences. 
Differences may reflect different traditions or different vaccine delivery systems.

Recollection of receipt of the tetanus vaccine was much higher than receipt of diphtheria (although a mere $17 \%$ of vaccine doses distributed for adult use contain only the tetanus antigen), indicating that people may receive Td or TdP vaccine without realizing they are being immunized against diphtheria. This results from a lack of information or from associating only tetanus as being administered following an injury. Although globulins should always be accompanied by a tetanus booster, in practice this is not always the case. People may confuse administration of immune globulins, which procures passive immunity, with administration of the vaccine when treated for a wound. This is further supported by the large proportion of vaccine doses administered in a hospital setting.

The same confusion between vaccine and globulins also applies to the hepatitis B vaccine. Three doses are required for primary vaccination. However, according to the replies and assuming persons were receiving one dose only, more doses would have been used than are currently distributed.

With the exception of vaccines for which there may be some confusion with administration of globulins (such as hepatitis B and tetanus) or for which a major lack of information exists (such as diphtheria), and within the limits of the cIs, the results seem quite valid. In particular they would generally agree with vaccine distribution figures.

Results suggest the need to improve coverage and to improve awareness about immunization in the adult population. Our results indicate that a maximum of $60 \%$ of adults would comply with NACI recommendations of a booster dose of tetanus every 10 years. Furthermore, a booster is often given after exposure as opposed to part of a routine immunization. This is demonstrated by the proportion of doses given in hospital settings. It is particularly striking to realize that more doses of yellow fever vaccine are being administered than doses of the pneumococcal vaccine. Our results regarding the influenza vaccine are consistent with the findings using the more precise but complicated methodology of the General Social Survey (4). We used the spring cycle to assess influenza vaccine coverage to minimize recall bias. A comparison of spring cycle with summer cycle results can determine whether recall bias was important. The spring cycle results are only $1 \%$ higher than the summer cycle results. It is nevertheless difficult to know if this difference is a real difference or merely due to chance. It is definitively not statistically significant.

The very limited availability of immunization records emphasizes how difficult it would be to evaluate vaccine coverage in adults directly. The results suggest poor vaccine coverage, poor immunization record keeping, poor awareness of immunization, and that these problems are not specific within a subgroup but that there is a general lack of interest or education about adult immunization in the general population. Some groups such as younger males and those with lower education and/or income levels should be particularly targeted by information campaigns or educational activities. Should education and promotion efforts be undertaken, a similar methodology could be useful in measuring progress accomplished in record keeping and awareness. We recommend using such studies to monitor evolution of vaccine coverage with the influenza vaccine. For vaccines rarely used, such as travellers' vaccines and pneumococcal vaccines, one could rely on the monitoring of vaccine distribution.

ACKNOWLEDGEMENTS: Thanks to Dr John Conly, Department of Medicine, University of Toronto, for his valuable advice and constructive critique of the manuscript.

\section{REFERENCES}

1. Korn JE, Poland GA. Adult immunization. Prim Care 1989;16:177-96.

2. National Advisory Committee on Immunization. Canadian Immunization Guide, 3rd edn. Ottawa: Ministry of Supplies and Services Canada, Department of National Health and Welfare, Cat No H49-8/1989E, 1989.

3. Conly JM. Anderson CM. Immunization in the elderly: a case of missed opportunities. Geriatrics 1991;46:35-45.

4. Duclos P, Hatcher J. Epidemiology of influenza vaccination in Canada. Can $J$ Public Health 1993:84:311-5.

5. Postcensal annual estimates of population by marital status, age, sex and components of growth for Canada, Provinces and Territories, June 1, 1992. Ottawa: Statistics Canada, Cat No 91-210, 1992;10.

6. Dagnelie P. Théorie et méthodes statistiques, Vol 2. Gembloux: Les presses agronomiques de Gembloux, 1975. 


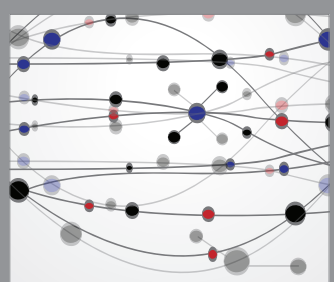

The Scientific World Journal
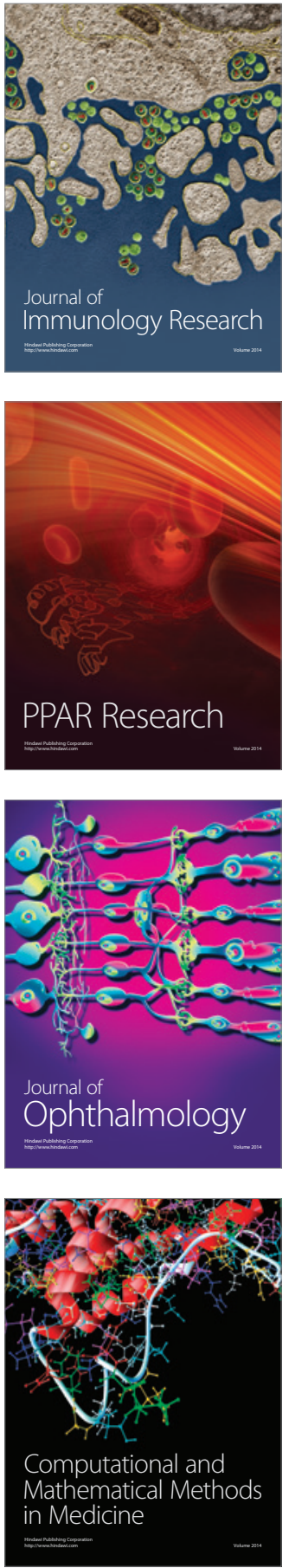

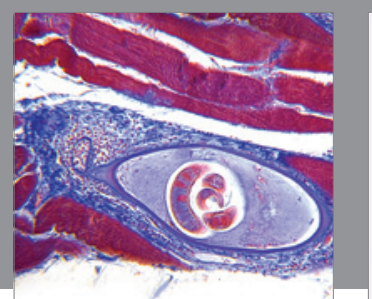

Gastroenterology Research and Practice

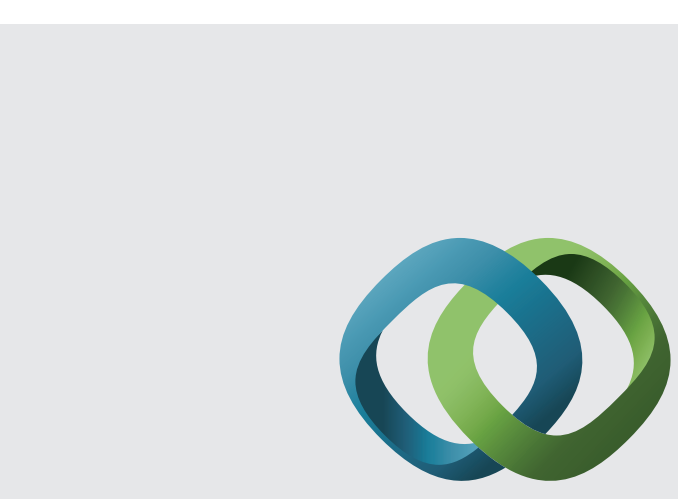

\section{Hindawi}

Submit your manuscripts at

http://www.hindawi.com
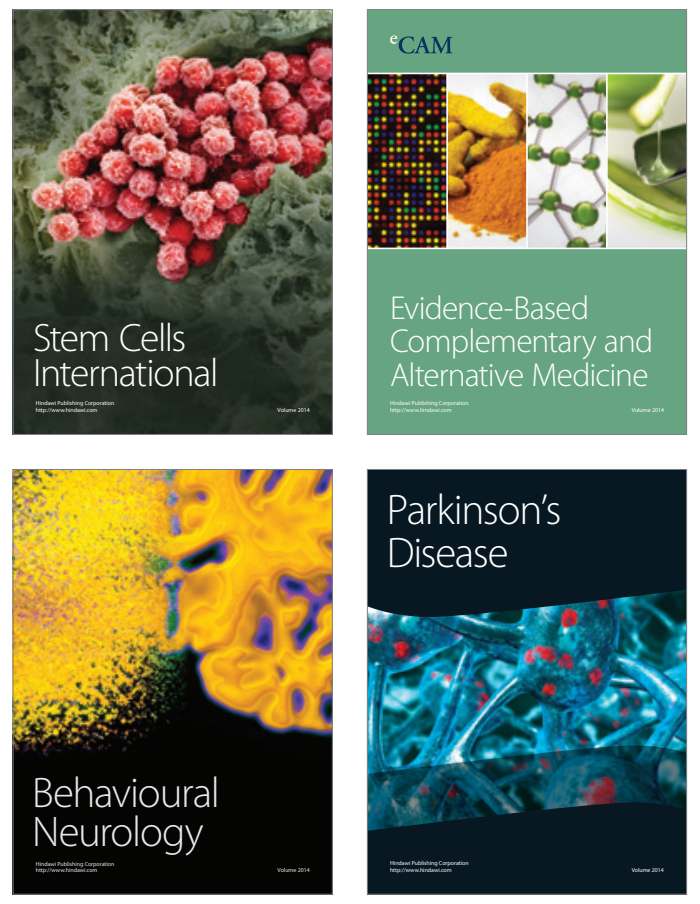
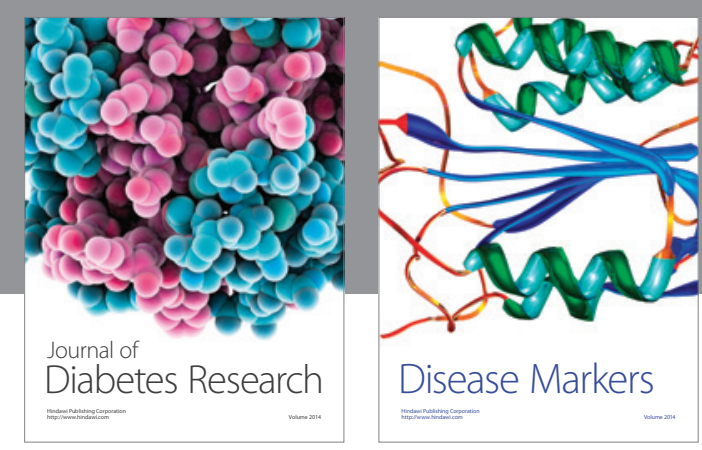

Disease Markers
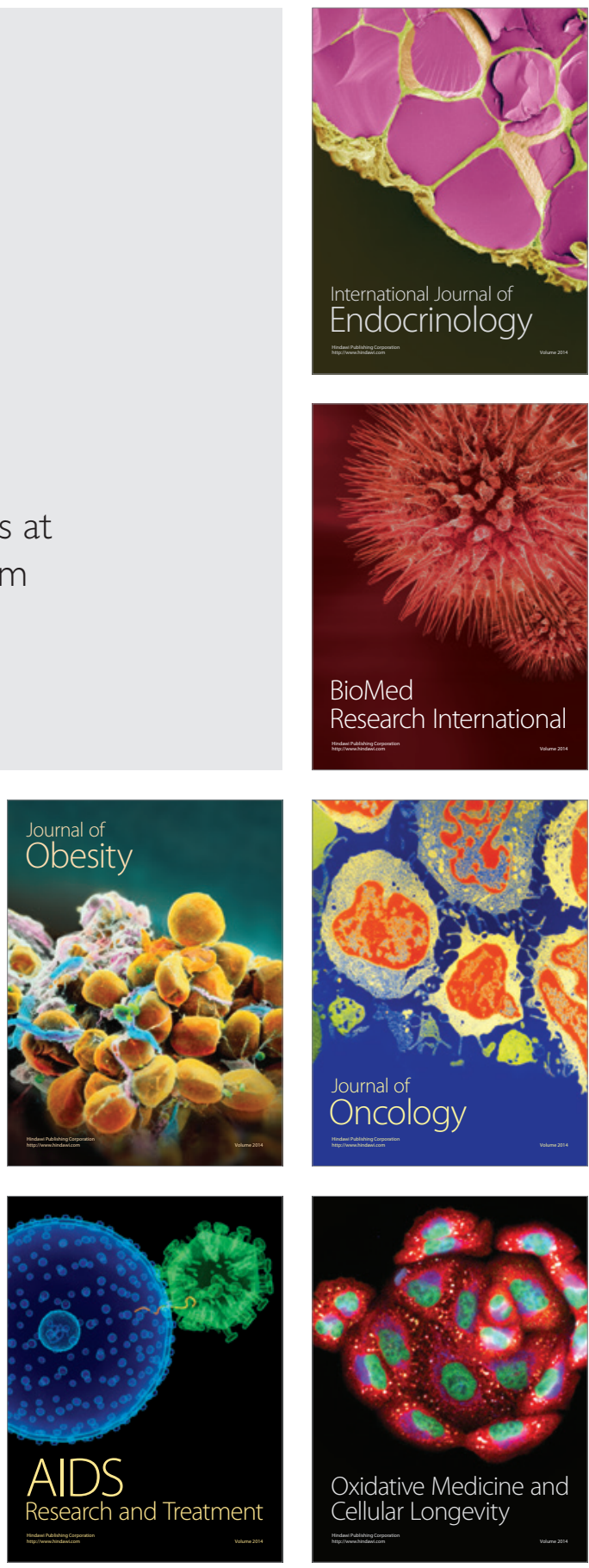